\title{
LOS EMPLEADOS DE LA RENTA DEL TABACO DURANTE LOS SIGLOS XVII Y XVIII: EL IMÁN DEL PRIVILEGIO
}

\author{
RAFAEL ESCOBEDO ROMERO \\ Universidad de Navarra*
}

RESUMEN: El Estado dotó a los empleados del monopolio real del tabaco de un régimen de privilegio con el doble propósito de facilitarles el ejercicio de sus funciones y, sobre todo, de estimular el servicio en la Renta mediante unas compensaciones económicas -y también sociales - que no repercutían en las finanzas reales sino que se trasladaban al conjunto de la masa social no privilegiada. El privilegio de estos empleados de la Real Hacienda fue controvertido, puesto que si bien suponía un perjuicio para el bien común, suponía también un ahorro de costes muy importante para el aparato recaudatorio del Estado.

Palabras clave: Renta del Tabaco. Real Hacienda. Privilegios. Empleados de rentas. Privilegios. Exención tributaria. Servicio militar.

ABSTRACT: The Spanish State gave many privileges and exemptions to the Royal Tobacco Tax Monopoly employees in order to help them to perform their functions and, above all, to encourage them to work in the Monopoly by means of economic - and also social-compensations that did not distress royal finances as they were supported by non-privileged people. Those privileges were controversial because they damaged the common good but, on the other hand, they meant a noteworthy cutback of the Royal Treasury disbursements.

KEY WORDS: $\quad$ Royal Tobacco Tax Monopoly. Spanish Royal Treasury. Treasury royal servants. privileges. Tax exemption. conscription.

* Siglas: AGS: Archivo General de Simancas

AHN, FC, MH: Archivo Histórico Nacional, Fondos Contemporáneos, Ministerio de Hacienda

DGR: Dirección General de Rentas. 
El sustancial fortalecimiento interno que experimentó el Estado español del siglo XVIII tuvo uno de sus fundamentos principales en el desarrollo de su aparato hacendístico. Toda vez que la verdadera modernización que hubiera significado el proyecto de Única Contribución de Ensenada quedó frustrado, los avances más relevantes se produjeron en el ámbito de la organización recaudatoria ${ }^{1}$. De entre los diversos recursos tributarios, los monopolios fiscales o rentas estancadas destacaron por la fluidez y abundancia de sus ingresos, así como por un cobro relativamente fácil desde el punto de vista administrativo y político. La acumulación de pequeñas (y a veces grandes) mejoras parciales fue marcando a lo largo del siglo una creciente eficiencia recaudatoria, sin modificar esencialmente el panorama tributario ${ }^{2}$. En este artículo nos vamos a centrar en una de esas políticas parciales que contribuyeron al desarrollo administrativo general, al tiempo que alteró de forma cada vez más sustancial los esquemas de relación social del Antiguo Régimen, concediendo una importancia cada vez más decisiva a las actividades de servicio al Estado sobre las viejas categorías de preeminencia social. Para ello, nos vamos a centrar en una Renta específica, la del Tabaco, el monopolio fiscal casi por antonomasia y el que proporcionó al Estado dieciochesco unos ingresos más sustanciosos ${ }^{3}$.

La Renta Real del Tabaco, como otras muchas ramas de la Real Hacienda, dotó a sus empleados de un régimen de privilegios y exenciones con la finalidad de hacer más efectivas sus funciones, al tiempo que se ofrecían interesantes alicientes personales. El régimen de privilegio de los servidores del rey en la Renta del Tabaco cobró especial importancia en los cuadros más bajos de la organización fiscal, puesto que es presumible que los elementos mejor posicionados ya tuviesen otros muchos medios para hacer valer sus condiciones de privilegio y exención. En este artículo analizaremos cómo la configuración de un estatus privilegiado para el personal del real estanco fue un proceso lleno de tensiones e intereses contrapuestos. El privilegio era un juego de suma cero, de modo que lo que beneficiaba a unos, a otros perjudicaba, o por lo menos dejaba de beneficiar. El privilegio era, como es bien sabido, una realidad consustancial al mundo europeo preliberal. El crecientemente fortalecido Estado monárquico del siglo XVIII no quiso ni pudo romper de raíz el orden social inmemorial definido desde la Edad Media, pero sí que quiso, e intentó siempre que pudo, reorientar el privilegio, la exención y la franqueza en el sentido más favorable

1 Cf. Artola, Miguel: La Hacienda del Antiguo Régimen, Madrid, 1982, pp. 224-319, PIEPer, Renate: La Real Hacienda bajo Fernando VI y Carlos III, Madrid, 1992, pp. 80-96; GonZÁLEZ ENCISO, Agustín: «La Hacienda castellana y la economía en el siglo XVIII», en Estudis (Valencia), 29 (2003), pp. 21-41.

2 Un ejemplo de este desarrollo administrativo puede verse para el caso de esta misma Renta del Tabaco en Escobedo, Rafael: El tabaco del rey. La organización de un monopolio fiscal durante el Antiguo Régimen, Pamplona, Eunsa, 2007, 351 pp.

3 Cf. GonZÁlez EnCiso, Agustín: "Tabaco y Hacienda, 1680-1820», en Actas del VIII Congreso de la Asociación de Historia Económica (Santiago de Compostela) (2005). 
para sus intereses. En algunos casos, los intereses del Estado entraron en colisión entre sí. Por ejemplo, cuando vemos chocar privilegios militares y hacendísticos. Cuando esto ocurría, el gobernante trataba de encontrar el equilibrio más idóneo entre los distintos cuerpos al servicio del rey. Cuando vemos que la Renta del Tabaco recibió en tantos casos la preferencia frente a otras realidades es porque el monopolio fiscal tabaquero era una de las principales fuentes de financiación del Estado, que llegó a recaudar por este concepto en torno a un quinto de sus ingresos ${ }^{4}$. A modo de círculo virtuoso, podría decirse igualmente que el hecho de que la Renta del Tabaco gozase de esta singular protección posiblemente contribuyó a su propia eficiencia recaudatoria. De todas formas, la acción privilegiadora del Estado no siempre respondía exactamente a los intereses del mismo Estado. Las instituciones - y los individuos que las componían- perseguían sus propios fines, de ahí que la suerte, las circunstancias y la habilidad con la que cada uno supiese bregar eran factores decisivos a la hora de obtener posicionamientos más o menos ventajosos.

En el caso de la Renta del Tabaco, esta situación de protección por medio del privilegio existió desde el mismo establecimiento del estanco en Castilla en $1636^{5}$, pero fue aumentándose y fortaleciéndose por la creciente importancia que el monopolio del tabaco fue adquiriendo en el conjunto de los ingresos fiscales de la Monarquía. La primera gran ampliación de exenciones y franquezas tuvo lugar en 1682, cuando se mejoró notablemente el estatus de los empleados tabaqueros, al igualárseles en derechos a los de Millones, impuesto con el que la Renta mantenía una teórica ligazón jurídica ${ }^{6}$. Entre 1684 y 1687, la Renta estuvo en directa administración por no hallarse arrendatario satisfactorio durante esos años ${ }^{7}$; cuando en 1687 se volvió a arrendar la Renta, las prerrogativas de 1682 se incorporaron al cuerpo contractual de los asientos ${ }^{8}$. En 1701, recién instalada en el trono la dinastía borbónica, se decidió no seguir arrendando la Renta del Tabaco al por mayor, nombrándose un superintendente encargado de negociar los arrendamientos provinciales, que subsistirían hasta la universal administración de $1731^{9}$. La cédula de 1701 por la que se estableció esta nueva planta del Tabaco confirmó y en algunos aspectos amplió los

4 Cf. GonZÁlez ENCISO, A.: «Tabaco y Hacienda, 1680-1820».

5 Real Cédula de 28/12/1636 (publicada en RoDRíGUEZ GordiLlo, José Manuel: La creación del estanco del tabaco, Madrid, 2002, pp. 159-191).

6 Real Cédula de 10/4/1682 (AHN, FC, MH, lib. 7389, folio 1 recto). Estas preeminencias se harían extensivas a los ministros del resguardo por Real Cédula de 7/11/1715 (AHN, FC, MH, lib. 7389, folio 81 recto).

7 Comín, Francisco/ Martín Aceña, Pablo: Tabacalera y el estanco del tabaco en España, 16361998, Madrid, 1999, p. 59.

8 Así se puede constatar por ejemplo en el traslado de la cédula que se inserta en el contrato con Pedro Parada en 1691 (AGS, Dirección General del Tesoro, inventario 4, leg. 30).

9 Escobedo, R.: El tabaco del rey..., p. 29. 
privilegios vigentes desde $1682^{10}$. Décadas más tarde, se imprimieron en varias ocasiones (al menos, en 1768, 1788 y 1799) modelos de títulos con estas prerrogativas, para que las llevasen consigo los beneficiarios, así como para su difusión a las autoridades, estableciéndose además multas de hasta 50.000 maravedíes para quienes contraviniesen las exenciones de los empleados del estanco ${ }^{11}$.

\section{CONTENIDO DEL RÉGIMEN PRIVILEGIADO}

Veamos a continuación en qué consistía básicamente este régimen privilegiado, de acuerdo con las cédulas de 1682 y 1701, más otros documentos que puedan servir de apoyo ${ }^{12}$.

\section{El fuero de Hacienda}

En primer lugar, los dependientes del Tabaco gozaban a todos los efectos del fuero de Hacienda. Aunque en esos dos momentos (1682 y 1701) todavía

10 Real Cédula de 28/5/1701 (publicada en Rodríguez Gordillo, José Manuel: Un archivo para la bistoria del tabaco, Madrid, 1984, pp. 76-79). Las Reales Cédulas de 2/5/1706 (AHN, FC, MH, lib. 8010, $\mathrm{n}^{\mathrm{o}} 215$ ) y de 12/7/1743 (AHN, FC, MH, lib. 7390, f. 14 recto), y la Real Orden de 27/1/1743 (AHN, FC, $\mathrm{MH}$, lib. 8015, $\mathrm{n}^{\mathrm{o}} 778$ ) insisten en los términos generales de la mencionada cédula de 1701 .

11 AHN, FC, MH, lib. 7390, f. 314 recto; lib. 7391, f. 284 recto; y, lib. 8051, no 5921.

12 Aparte de lo que iremos citando a lo largo del artículo, la legislación que insistió la vigencia -más los convenientes matices de cada ocasión- de diversos aspectos de este régimen aforado fue muy abundante: Órdenes de 19/6/1737 (AHN, FC, MH, lib. 7389, f. 224 vuelto), 22/2/1736 (íb., f. 214 vuelto), 4/11/1734 (íb. f. 205 vuelto) y 4/4/1733 (íb., f. 203 vuelto), Reales Cédulas de 12/8/1713 (íb., f. 72 vuelto), 15/2/1739 (íb., f. 248 vuelto), 24/3/1711 (íb., f. 57 recto), 26/5/1708 (íb., f. 43 recto) y 7/11/1715 (íb., f. 81 recto), Real Orden de 27/11/1740 (íb., f. 311 recto), Real Provisión de 9/7/1731 (íb., f. 197 recto), Reales órdenes de 22 y 23/9/1739 (íb., folios 251 recto y 252 recto), Órdenes de 27/8, 14/10, 29/10 y 3/11/1767 (AHN, FC, MH, lib. 7390, f. 312 recto), Reales Cédulas de 12/7/1743 (íb., f. 14 recto), 3/10/1747 (íb., f. 61 recto) y 8/7/1743 (íb., f. 21 vuelto), Órdenes de 10/12/1708 (AHN, FC, MH, lib. 8010, $\mathrm{n}^{\circ}$ 231), 16/1/1709 (íb., $\mathrm{n}^{\mathrm{o}} 233$ ) y 9/2/1709 (íb., no 234), Real Cédula de 2/5/1706 (íb., no 215), Orden de 28/6/1738 (AHN, FC, MH, lib. 8013, $\mathrm{n}^{\circ}$ 623), Real Cédula de 11/11/1747 (AHN, FC, MH, lib. 8015, $\mathrm{n}^{\circ}$ 928), Reales Órdenes de 27/1/1743 (íb., no 778), 22/10/1751 (AHN, FC, MH, lib. 8018, no 1244), 8/6/1754 (AHN, FC, MH, lib. 8019, no 1369) y 26/1/1757 (AHN, FC, MH, lib. 8020, no 1482), Órdenes de 9/2/1795 (publicada en GALLARDO, Francisco: Origen, progreso y estado de las Rentas de España, su gobierno y administración, Madrid, 1805, p. 294), 10/5/1799 (publicada en íb., p. 266) y 14/5/1795 (publicada en íb., p. 295), Reales Órdenes de 22/4/1790 (publicada en íb., p. 107), 3/3/1784 (publicada en íb., p. 154), s.f./7/1799 (publicada en íb., p. 262), 26/12/1797 (publicada en LóPEZJuana Pinilla, José: Tratado teórico-práctico de los Juicios de Contrabando, Madrid, 1825, p. 304) y 28/5/1791 (publicada en SÁNCHEZ, Santos: Colección de pragmáticas, cédulas, provisiones, autos acordados $y$ otras providencias generales expedidas por el Consejo Real en el reinado del señor don Carlos IV, tomo I, Madrid, 1805, $3^{\text {a }}$ ed., pp. 159-160). 
los dependientes del estanco no eran propiamente servidores del rey sino empleados de un empresario particular, su condición personal era plenamente la de dependientes de la Real Hacienda. Como tales aforados de Hacienda, todas las causas, tanto las civiles como las criminales, eran de jurisdicción exclusiva del subdelegado o juez conservador de rentas reales, inhibiéndose todos los demás tribunales ${ }^{13}$. La apelación de las causas se elevaba a la Sala de Millones del Consejo de Hacienda. En la prerrogativa del fuero nos encontramos inequívocamente con la doble intencionalidad del privilegio a la que antes nos referíamos. La exclusividad jurisdiccional impedía que el desempeño propio de los empleados del Tabaco pudiese ser objeto de controversia judicial fuera del espacio controlado por la administración hacendística, evitándose cualquier posible menoscabo de los intereses del Erario que por esta vía pudiese tener lugar. Era una manera de cerrar el paso a intromisiones indirectas de poderes distintos a los de la Real Hacienda, incluso provenientes de la misma Administración del Estado, en el ámbito propio de la materia fiscal. Qué duda cabe de que, además, este amparo jurisdiccional resultaba enormemente apetecible para los empleados del estanco, individualmente considerados. Uno de los 'bienes jurídicos' más codiciados del Antiguo Régimen era el aforamiento. El aspecto retributivo de esta condición derivada del servicio en el estanco tabaquero es más que evidente. La vigencia de este fuero fue numerosas veces insistida ante los conflictos jurisdiccionales que con cierta frecuencia acaecieron. Así por ejemplo, el gobernador de Llerena intentó procesar al administrador y a unos guardas en 1715 14 ; el justicia ordinario de Cebolla intentó lo mismo en $1739^{15}$; en 1734 se quejaba la Dirección de la frecuencia con que con cualquier pretexto se introducen las justicias ordinarias a proceder contra los dependientes de la Renta en Valencia ${ }^{16}$; y, en 1791 se dispuso que si las justicias prendiesen a un empleado de la Renta diesen cuenta a sus jefes en el mismo acto ${ }^{17}$.

\section{Derecho a portar armas}

En la misma línea nos encontramos la concesión del derecho de portar armas, tanto ofensivas como defensivas, excepto las prohibidas, a cualquier hora y lugar, así como vara alta y corta de justicia. Las licencias que individualmente habilitaban para el ejercicio de este derecho se expedían por los subdelegados. Hasta 1716 era necesaria una real cédula expedida por el superintendente de Hacienda, pero a partir de ese año se capacitó para ello al superintendente de

13 Cf. Escobedo, R.: El tabaco del rey..., pp. 46-54.

14 AGS, DGR, $2^{\text {a }}$ remesa, leg. 4800, fecha de expediente: 23/8/1715.

15 AGS, DGR, $2^{\text {a }}$ remesa, leg. 4662, fecha de expediente: 31/10/1739.

16 AGS, DGR, $2^{\mathrm{a}}$ remesa, leg. 4806, fecha de expediente: 20/2/1734.

17 Real Orden de 28/5/1791 (publicada en SÁNCHEZ, S.: Colección..., I, pp. 159-160). 
la Renta y a sus subdelegados ${ }^{18}$. En 1797, incluso adquirieron validez las expedidas por los administradores y por los comandantes del resguardo ${ }^{19}$. A partir de 1739, también gozaron de la prerrogativa de portar armas unos individuos que ciertamente las necesitaban, los conductores de caudales de la Renta, a pesar de que orgánicamente no tenían por qué pertenecer necesariamente a la Renta ${ }^{20}$.

No cabe duda de que la intención del legislador se encaminaba a armar, en el sentido más literal de la palabra, a los dependientes, y en especial a los del resguardo, en sus responsabilidades contra el fraude, así como para garantizar a los estanqueros seguridad en sus establecimientos. Pero tampoco cabe duda de que, además, el privilegio de portar armas confería un reconocido estatus social, que marcaba una diferencia neta con el resto de la gente. El gobierno de la Renta se encontró innumerables veces y en los más variados lugares y circunstancias con disposiciones contrarias al ejercicio de esta prerrogativa, que siempre defendió celosamente, por considerarla vital para el buen funcionamiento del estanco. Los ejemplos son numerosos en este sentido. En 1716 la Superintendencia protestó de la prohibición de uso de armas de fuego que hizo extensiva el capitán general de Valencia a los del Tabaco ${ }^{21}$. En octubre de ese mismo año, los gobernadores de Cádiz, Puerto de Santa María y Cartagena incluyeron a los ministros del estanco en la prohibición de armas ofensivas cortas; el superintendente general de la Renta se quejó de que

se vieron precisados a desarmarse inmediatamente, quedando con la mayor desconfianza de poder conseguir el resguardo de la Renta, porque siendo la esencial circunstancia de lograrse las diligencias y aprehensiones el disimulo y secreto con que ejecutan y solicitan, mal podrán hacerlas con el habiendo de llevar manifiestas las armas largas de que usarán hoy, y con que irán publicando ser ministros de las rentas 22 .

En 1719, un alcalde de la chancillería de Granada puso presos a los arrendatarios Juan Soriano y Francisco Ruiz por portar armas de fuego; protestó el intendente subdelegado, pero por Real Resolución se prescribió que los ministros usen sólo de las armas probibidas cuando estén en diligencias de su oficio 23 . En 1722 volvieron a suscitarse dudas a raíz de la publicación de una pragmática que prohibía el uso de armas de fuego cortas y demás ofensivas. El superintendente se hizo eco de las numerosas representaciones enviadas por subdelegados, admi-

18 Real Orden de 12/8/1716 (AGS, DGR, $2^{\mathrm{a}}$ remesa, leg. 4800).

19 Real Orden de 26/12/1797 (publicada en LóPeZ-JuAna Pinilla, J.: Tratado teóricopráctico..., p. 304).

20 Real Cédula 15/2/1739 (AHN, FC, MH, lib. 7389, f. 248 vuelto).

21 AGS, DGR, $2^{\mathrm{a}}$ remesa, leg. 4800, fecha de expediente: 1/8/1716.

22 AGS, DGR, $2^{\mathrm{a}}$ remesa, leg. 4800, fecha de expediente: 1/10/1716.

23 Real Resolución de 30/1/1719 (AGS, DGR, 2a remesa, leg. 4801). 
nistradores y arrendatarios de distintas provincias sobre si, a pesar de las cédulas en vigor, les alcanzaba a ellos el decreto, pidiendo al rey un nuevo expreso reconocimiento de la prerrogativa ${ }^{24}$. En 1729, la Dirección General de la Renta achacó al no reconocimiento de este derecho la pérdida en Cádiz de una aprehensión de fraudes ${ }^{25}$. A partir de 1739, con la real cédula antes mencionada, parece que ya no se cuestionó más el derecho de los dependientes de la Renta a portar armas.

\section{Privilegios de los conductores de tabaco, caudales y reos}

Los conductores al servicio de la Renta, ya fuese de tabacos, caudales o reos, de los que ya hemos dicho que no necesariamente tenían que pertenecer orgánicamente al estanco, también gozaban de ciertas prerrogativas, dirigidas fundamentalmente a facilitar su labor y hacerla lo menos onerosa posible para el Estado. Ya hemos señalado la autorización que tenían de llevar armas, pero sobre todo, estos transportistas quedaban exentos del pago de los distintos derechos de paso que se establecían en las redes viarias españolas, de lo cual en el modelo de títulos de 1788 se excluyó expresamente a todos los demás dependientes. Sin embargo, este mismo documento no hizo comprensivo para los conductores ni la exención — de la que nos ocuparemos más adelante- de alojamientos, ni tampoco la de bagajes,

limitada a las solas caballerías que deben partir el día mismo del embargo con los efectos de la Real Hacienda, pues las demás caballerías que existan en el distrito de su jurisdicción deben ser incluidas en el repartimiento.

Además, tenían, como las tropas militares, derecho a ser alojados:

en los pueblos en que no haya posada para el preciso descanso de sus personas y caballos y para la custodia de los efectos que conduzcan, así como reos, personas o animales enfermos.

Por último, si lo necesitasen, las justicias debían auxiliarles en la custodia de los reos ${ }^{26}$. En cuanto a todo esto, desconocemos fehacientemente cual era la praxis anterior a la tardía fecha de este modelo de títulos de 1788.

24 AGS, DGR, $2^{\mathrm{a}}$ remesa, leg. 4802, fecha de expediente: 19/5/1722.

25 AGS, DGR, $2^{\text {a }}$ remesa, leg. 4804, fecha de expediente: 8/8/1729. En el mismo sentido: AGS, DGR, $2^{a}$ remesa, leg. 4808, fecha de expediente: 23/7/1734.

26 Modelo de títulos s.f./1788 (AHN, FC, MH, lib. 7392, f. 284 recto). 


\section{Exenciones tributarias}

La condición de empleado de Hacienda conllevó también la no sujeción en general a las obligaciones militares y a la fiscalidad municipal. Esta situación exenta se revelaba particularmente conflictiva, puesto que en las localidades más pequeñas suponía que los demás vecinos no privilegiados debían asumir la parte de esfuerzo de la que se libraban los individuos exceptuados, con el consiguiente conflicto social al que haremos referencia.

Respecto a la fiscalidad local se hallaban libres de todas cargas y oficios concejiles, de cobrar pechos, padrones de bulas, moneda forera, alcabalas y repartimientos de puentes, curadurías ni otros algunos, (...) portazgos, pontazgos y barcajes, así como salir en justas o trabajos. A partir de 1731, la situación de los empleados del Tabaco quedó mejor incluso que la de los de otros ramos de la Hacienda, ya que fueron restablecidas para aquéllos las exenciones que se habían suprimido en 1728 con carácter general para todos los empleados del Erario ${ }^{27}$. Esta situación sería recordada insistentes veces, en unas ocasiones simplemente de forma genérica $^{28}$, y en otras para convencer por la vía del decreto a las autoridades renuentes así como para contrarrestar el efecto de las disposiciones que se emitieron en sentido contrario. Ejemplo de esto fueron las que se tuvieron que proveer para garantizar la exención de cargas concejiles en Aragón ${ }^{29}$ o de los barcajes, pontazgos y portazgos en $1757^{30}$.

Sin embargo, las matizaciones y esclarecimiento de casuísticas fueron también numerosas. En 1736, a instancias de un pedimento enviado a la Junta del Tabaco por el diputado del Principado de Asturias José Miguel de Heredia ${ }^{31}$, se aclaraba que los ministros y los empleados del Tabaco de Asturias debían pagar los repartimientos que les perteneciesen como vecinos de los pueblos, distinguiéndolos de las cargas concejiles de las que estaban exentos, si bien no queda claro si se trataba de una particularidad privativa del principado asturiano ${ }^{32}$.

27 Real Orden de 26/5/1728 (AHN, FC, MH, lib. 8012, no 498) y Real Provisión de 9/7/1731 (AHN, FC, MH, lib. 7389, f. 197 recto).

28 AGS, DGR, $2^{\text {a }}$ remesa, leg. 4662, expediente s.f./1736; Real Cédula de 27/6/1742, aludida en AGS, DGR, $2^{\mathrm{a}}$ remesa, leg. 4663, fecha de expediente: 29/7/1749; Real Orden de 27/1/1743 (AHN, FC, $\mathrm{MH}$, lib. 8015, $\mathrm{n}^{\circ}$ 778), Reales Cédulas de 8/7/1743 (AHN, FC, MH, lib. 7390, f. 21 vuelto), 12/7/1743 (ib., f. 14 vuelto), 3/10/1747 (ib., f. 61 recto) y 11/11/1747 (AHN, FC, MH, lib. 8015, no 928).

29 AGS, DGR, $2^{\text {a }}$ remesa, leg. 4808, fecha de expediente: 27/7/1734. Las divergencias terminológicas provocaron controversias: Esta exención de que generalmente gozan en todos los dominios de Su Majestad los dependientes de la Renta, se les dificulta en el reino de Aragón (...) sólo porque allí tienen las cargas concejiles distintos nombres de aquellos con que se explican en Castilla (AGS, DGR, $2^{\mathrm{a}}$ remesa, leg. 4806, fecha de expediente: 15/3/1736).

30 Real Orden de 26/1/1757 (AHN, FC, MH, lib. 8020, n $^{\circ}$ 1482). Por Real Orden de 8/6/1754 (AHN, FC, MH, lib. 8019, n 1369) ya se había prescrito la exención de pontazgo en el puente sobre el Jarama.

31 AGS, DGR, $2^{\text {a }}$ remesa, leg. 4667, fecha de expediente: 16/2/1736.

32 Orden de 22/2/1736 (AHN, FC, MH, lib. 7389, f. 214 vuelto). 
Años más tarde, en 1767 , se hizo la precisión de que los dependientes de la Renta no estarían libres de las cargas vecinales si fuesen vecinos, pero sí si estuvieren en la localidad en comisión de servicio ${ }^{33}$. Respecto al pago de millones, se prescribió ese mismo año que todos los referidos empleados, por sus personas y las de sus familias, no teniendo otros tratos, industrias, comercios ni haciendas, sólo deben pagar lo justo que les toque por razón del consumo de las especies de millones y nada más ${ }^{34}$. Una Real Orden de 1784 aclaró que ningún cargo municipal podría ampararse en su fuero hacendístico si se le encausase por sus acciones en el gobierno de la localidad $^{35}$. Por último, en 1790 , en un momento en el que la construcción de redes camineras estaba atrayendo una atención gubernamental preferente, se levantó la exención que pudiera colegirse de la legislación en relación con la contribución de caminos ${ }^{36}$. Como vemos, a lo largo del tiempo se dio un continuo tira y afloja en relación al alcance de las exenciones tributarias de los empleados de la Renta.

\section{Exención de obligaciones militares}

Las obligaciones de los municipios para con la Corona iban mucho más allá de la mera aportación dineraria. Durante el siglo XVIII se generalizó en España la conscripción por medio de quintas para completar, junto con la recluta voluntaria y la leva de vagos, los contingentes de tropa de los Reales Ejércitos. Cada localidad debía aportar su contingente de quintos para el servicio militar, o su redención en metálico según determinadas condiciones. Pues bien, los empleados del Tabaco quedaron generalmente exentos de quintas y redenciones. En los años de la guerra de Sucesión se insistió varias veces la exención de obligaciones militares de los miembros del estanco, particularmente en los territorios aragoneses, donde se desarrollaron las últimas fases del conflicto, en los años 1708, 1709 y $1711^{37}$. Sin embargo en el conflicto bélico que siguió casi a continuación, las campañas de revisión del tratado de Utrecht en Cerdeña y Sicilia, ni la sostenida política de protección a la Renta pudo resistir los planes italianos de Isabel de Farnesio, disponiéndose en octubre de 1718 — cuando la guerra se complicaba por momentos en el escenario siciliano-, por ser urgente la precisión de hacerla, el levantamiento de la exoneración de entrar en los sorteos de levas ${ }^{38}$.

33 Órdenes de 27/8, 14/10, 29/10 y 3/11/1767 (AHN, FC, MH, lib. 7390, f. 312 recto). Asimismo, por Real Orden de 3/3/1784 (publicada en GALLARDO, F.: Origen..., p. 154): que ningún dependiente se eximiese por su fuero de los cargos de que debiese responder si fuese de ayuntamiento.

34 Real Orden de 26/11/1767, citada en el modelo de títulos s.f./1788 (AHN, FC, MH, lib. 7392, f. 284 recto).

35 Real Orden de 3/3/1784 (publicada en Gallardo, F.: Origen..., p. 154).

36 Real Orden de 22/4/1790 (publicada en Gallardo, F.: Origen ..., p. 107).

37 Real Orden de 10/12/1708 (AHN, FC, MH, lib. 8010, no 231), Órdenes de 16/1/1709 (íb., $n^{\circ} 233$ ) y 9/2/1709 (íb., no 234), y Real Cédula de 24/3/1711 (AHN, FC, MH, lib. 7389, f. 57 recto).

38 Real Resolución de 10/10/1718 (AGS, DGR, $2^{\mathrm{a}}$ remesa, leg. 4801). 
Cuando las urgencias dinásticas se atenuaron, los empleados del Tabaco recuperaron sus prerrogativas ${ }^{39}$. El modelo impreso de título de exenciones de 1788 excluyó de la excepción de quintaje a los guardas, tanto de a pie como de a caballo, que prestaban servicio en la Renta ${ }^{40}$. Finalmente, el problema volvió a plantearse con la guerra de la Convención: en febrero de 1795 se volvió a recordar que estaban exentos ${ }^{41}$, pero muy poco después, en mayo, se ordenó que sí acudiesen a la guerra los que careciesen de plazas fijas en el servicio ${ }^{42}$.

Como vemos, en tiempos de paz normalmente no surgían conflictos, pero cuando se declaraba una guerra, las distintas autoridades militares recibían la consigna de evitar que la maraña de fueros y franquezas, cuyo conocimiento en detalle era a veces un verdadero arcano, pudiese significar un subterfugio para aquellos que quisiesen evadirse de sus obligaciones militares. Los conflictos jurisdiccionales se volvían a plantear en todo su esplendor, sostenidos por una legislación confusa, compleja y en numerosas ocasiones contradictoria. Las jerarquías locales de la Renta se enfrentaban en tales momentos a fuertes presiones por parte de las autoridades militares. La Hacienda, veladora de sus intereses, insistía en la normativa vigente, si bien precisándola y explicándola con claridad, para evitar malinterpretaciones maliciosas, tanto por parte de las autoridades militares como por parte de los empleados de la Renta. Un buen ejemplo de esta casuística nos lo encontramos en 1733, cuando se estableció que los dependientes de la Renta habían de ser casados, para evitar que los administradores no abusasen de nombramientos destinados únicamente a librar a mozos de las quintas ${ }^{43}$, o la exclusión en 1753 de la exención de los administradores y estanqueros menores de 25 años ${ }^{44}$.

Un caso aparte en lo relativo a la exención de servicio militar es la que gozaban los capitanes y marineros del resguardo, quienes quedaban libres de servir en la Marina para seguir persiguiendo el contrabando que se introducía por vía marítima. Los ejemplos son múltiples: en 1720 se eximió de la leva a los marineros del resguardo marítimo de Alicante y Castro Urdiales ${ }^{45}$, y en 1739 se declaró que a los marineros y patronos de barcos de la Renta del Tabaco se les conceda el mismo indulto que a los asentistas de víveres de los presidios, dejándoles en quietud en sus destinos ${ }^{46}$. El

39 Reales Resoluciones de 4/8/1719 (AGS, DGR, $2^{\mathrm{a}}$ remesa, leg. 4801), sobre exención de reparto de bagajes en Aragón, y de 1/3/1720 (AGS, DGR, $2^{\mathrm{a}}$ remesa, leg. 4801), sobre no inclusión en sorteos y quintas también en Aragón; diferentes resoluciones del año 1720 (AGS, DGR, $2^{\text {a }}$ remesa, leg. 4801) sobre el ilegal reparto que las justicias de Cuatro Villas habían hecho de alojamiento de tropas y reparto de ropa de cama.

40 Modelo de títulos s.f./1788 (AHN, FC, MH, lib. 7392, f. 284 recto).

41 Orden de 9/2/1795 (publicada en Gallardo, F.: Origen..., p. 294).

42 Orden de 14/5/1795 (publicada en íb.)

43 Orden de 4/4/1733 (AHN, FC, MH, lib. 7389, f. 203 vuelto).

44 Real Orden de 24/3/1753 (AGS, DGR, $2^{\mathrm{a}}$ remesa, leg. 4664).

45 AGS, DGR, $2^{\mathrm{a}}$ remesa, leg. 4661, fecha de expediente: 31/7/1728.

46 Reales Órdenes de 22 y 23/9/1739 (AHN, FC, MH, leg. 7389, folios 251 recto y 252 recto). 
resguardo de Almuñécar se quejó en julio del año siguiente de que se estaban haciendo levas sobre los marineros ${ }^{47}$. No obstante, esta legislación favorable a la Renta se anuló en noviembre de ese mismo año de 1740 por las necesidades de la guerra, eminentemente naval, de la oreja de Jenkins ${ }^{48}$. En 1787 se declaró que los marineros del resguardo marítimo deberían ir a hacer campaña cuando les toque, librándose los patrones, a no ser que el administrador dispusiese lo contrario. Es de suponer que esta exención para los patrones tenía como finalidad que pudiesen reclutar interinos y seguir con el manejo profesional del resguardo marítimo ${ }^{49}$.

\section{Exención de prestaciones personales}

Ante las carencias de una todavía muy incipiente arma de intendencia, los súbditos estaban obligados a prestar alojamiento y alimentación a las tropas y sus caballerías en tránsito por los pueblos. También de este tipo de obligaciones fueron considerados generalmente exentos los empleados del Tabaco ${ }^{50}$. Es bien conocido que estas exigencias 'para-fiscales' fueron verdaderamente devastadoras en ciertos lugares, donde el tránsito de militares se hizo 'endémico'. Pero además se daba la circunstancia de que precisamente eran los lugares donde abundaban los soldados y militares donde se registraba un mayor consumo de tabaco, de modo que la ratio de expendedurías por habitante de derecho probablemente se redujese sensiblemente respecto a la de parajes menos transitados por las gentes de armas. Más tarde, en 1738, se admitió que en caso de que fuese necesario acudir a las casas de los exentos, por estar cubiertas las de los no exentos, se hiciese en rigurosa proporción ${ }^{51}$. Sin embargo, los incidentes, conflictos y malentendidos entre los empleados del Tabaco y las autoridades continuaron produciéndose ocasionalmente, cuando aquéllos trataban de hacer valer sus derechos frente a éstos, como ocurrió en 1730 cuando el corregidor de Jerez de la Frontera puso en arresto domiciliario al administrador de la ciudad por no haber admitido alojar a un guardia de corps ${ }^{52}$.

47 AGS, DGR, $2^{\mathrm{a}}$ remesa, leg. 4808, fecha de expediente: 22/7/1740.

48 Real Orden de 27/11/1740 (AHN, FC, MH, leg. 7389, f. 311 recto).

49 Real Resolución de 7/11/1787 (publicado en Ripia, Juan de la/ GaLLARD, Diego María: Práctica de la administración y cobranza de las rentas, tomo V, Madrid, 1795, $6^{\mathrm{a}}$ ed., p. 619).

50 Los subdelegados, sólo por su condición de tales, no estaban comprendidos en esta exención. Este es el sentido de la Real Resolución de 30/9/1717 (AGS, DGR, $2^{\mathrm{a}}$ remesa, leg. 4800), en respuesta a la instancia del subdelegado de Ocaña. Es un caso particular, porque normalmente las personas que ostentaban las subdelegaciones ya gozaban de exenciones por otros motivos. También quedaron exentos de embargos de caballos u otros animales de carga (AGS, DGR, $2^{\text {a }}$ remesa, leg. 4801, fecha de expediente: 19/6/1719), cuando los intendentes de Andalucía llevaron a cabo un embargo de caballos.

51 Orden de 28/6/1738 (AHN, FC, MH, lib. 8013, nº 623).

52 AGS, DGR, $2^{\text {a }}$ remesa, leg. 4804, fecha de expediente: 25/9/1730. 
Cierta similitud con estas obligaciones militares y concejiles tuvieron las que también surgieron en determinadas comarcas en relación con el abastecimiento obligatorio, y fuera de los circuitos propios del mercado, de determinados bienes a la Corte y otras ciudades importantes: ni bagajes, ni trigo, ni cebada, ni pan cocido para la Corte, ni para otra partes3.

\section{EL SERVICIO DEL REY Y EL BIEN COMÚN: LA CONTROVERSIA ALREDEDOR DEL PRIVILEGIO}

Qué duda cabe de que esta política de privilegios y exenciones hay que entenderla también como una manera de distribuir el peso de la Renta en otros hombros aparte de los del rey. De este modo, el costo del estanco no era asumido únicamente por el Estado, es decir, que no lo podemos sólo calcular sobre la diferencia entre producto bruto y neto, sino que hay que tener en cuenta este importante sostenimiento indirecto de la Renta por parte de los municipios. Esta distribución del esfuerzo para sostener la Renta generó inevitablemente vivas reacciones de los que individual o colectivamente se sintieron perjudicados. Independientemente del importantísimo hecho de que ser sujeto de algún tipo de régimen de privilegio ya de por sí significaba una especie de elemental ascenso social sobre la masa no privilegiada, lo más importante del fuero del Tabaco era eso otro mucho más tangible que significaba verse libre de las numerosas y ominosas obligaciones fiscales y 'para-fiscales' que hemos descrito más arriba. Estas exenciones les dejaban fuera del sostenimiento económico de los pueblos o ciudades donde residían, así como de buena parte de la fiscalidad estatal que se recaudaba a través de los municipios. De este modo, el Estado se aseguraba una demanda de empleo tanto en calidad como en cantidad, y también en parte la fidelidad de sus dependientes, pagando de este modo lo que no podría gastar en dinero. No hemos cuantificado cuánto podían llegar a significar para los bolsillos de los dependientes las exenciones de su empleo, ni cuánto podían significar dichos 'no gastos' en relación con los ingresos salariales; en cualquier caso, parece que sin los privilegios, el empleo en la Renta perdía buena parte de su atractivo. Al ser un bien deseado y codiciado, quienes pudieron acceder a él fueron lógicamente quienes gozaron de mayor capacidad para obtenerlo, esto es, aquellos elementos de la sociedad relacionados con las redes de asentistas o con contactos influyentes en la Administración, personas en definitiva con algo que ofrecer, con algo con lo que negociar. El empleo en la Renta por lo tanto pudo ser alcanzado por elementos más o menos acomodados de los lugares de su residencia; no fueron, pues, las bases del Tabaco de lo menos afortunado de la sociedad, sino que más bien podríamos estar ante incipientes burguesías locales. No obstante la Renta del Tabaco

53 Modelo de títulos s.f./1788 (AHN, FC, MH, lib. 7392, f. 284 recto). 
no fue la primera ni la última institución capaz de ofrecer este tipo de ventajas, de modo que nos encontramos cómo en las ciudades y más todavía en los pueblos, los mejor posicionados social y económicamente solían estar libres ya de las obligaciones fiscales y feudales repartidas entre los no exentos. Otros ya habían ganado anteriormente sus parcelas de exención y privilegio en instituciones tales como la Santa Hermandad, Cruzada, familiares de la Inquisición, etcétera. Una Real Orden de mayo de 1728 trató de poner coto de forma expeditiva a este estado de cosas. El preámbulo de la disposición no puede ser más expresivo del escenario al que nos estamos refiriendo:

Teniendo presente los perjuicios que se siguen a mi real servicio, a los vasallos pobres y a la causa pública de estos reinos el crecido número que hay de personas exentas de oficios y cargas concejiles, alojamientos de tropas y repartimientos de bagajes y paja para ellos, con motivo de ministros y hospederos de Cruzada, familiares y ministros del Santo Oficio, hermanos y síndicos de religiones, ministros de rentas reales, guardas de ellas, estanqueros de naipes, tabaco, pólvora y otros géneros, comisarios de las Santas Hermandades, salitreros, dueños de yeguas y otros así, por no contenerse los tribunales en nombrar sólo aquellos precisos de número, como por la abusiva negociación que se hace por muchos vecinos acomodados para obtener semejantes títulos de los arrendadores de rentas reales y otros que alegan tener facultad para concederlos, de la cual se valen para establecerlos sin necesidad, aun en pueblos de corta población, de que se reconoce con evidencia no ser otro el fin de la solicitud de estos títulos que la utilidad de gozar exención de las referidas cargas, que, por este motivo, recaen necesariamente sobre los vecinos pobres y que menos pueden llevarlas; de que resultan al mismo tiempo dos gravísimos daños: el uno a las tropas, que en lugar del descanso y alivio que deben gozar en el alojamiento, encuentran necesidades que las afligen; y el otro más principal, que no pudiendo los vecinos pobres sobrellevar solos tan pesadas cargas, se ven precisados a desamparar sus casas y lugares, metiéndose a mendigos; de que se sigue, sin duda, además de los perjuicios que ocasionan la gente ociosa, verse tantos pueblos arruinados y sin gente para el cultivo de los campos y otros ministerios precisos, cuyos dolorosos efectos son tan ciertos como trascendentales a casi toda España. (...) el desorden o abuso de exentos en los pueblos, especialmente por lo que mira a alojamientos, es uno de los puntos de interés público que más ejecuta a la obligación y caridad para un pronto y eficaz remedio 54 .

Los argumentos con los que los directores de la Renta del Tabaco protestaron esta medida nos ofrecen el soporte teórico al que antes hacíamos referencia, que puede resumirse básicamente en que la existencia de los privilegios aseguraba la rentabilidad del estanco: de subsistir la suspensión e inobediencia de las exenciones (...) la Renta del Tabaco irá decayendo en sus valores hasta su ruina ${ }^{55}$. De este modo, y después de reconocer que efectivamente las exenciones habían dado lugar a muchas situaciones injustas y dañinas, así como de lamentar que los

54 Real Orden de 26/5/1728 (AHN, FC, MH, lib. 8012, no 498).

55 AGS, DGR, $2^{\mathrm{a}}$ remesa, leg. 4661, fecha de expediente: 31/7/1728. 
concejos se habían lanzado a cargar, incluso con efectos retroactivos a los empleados de la Renta, la Dirección recordó que

para que la Renta del Tabaco [se] estableciera en el buen régimen, respeto y resguardo que afianzase sus aumentos fue Su Majestad servido (a tiempo que se dignó deliberar su administración por cuenta de la Real Hacienda, que fue el año de 1701) privilegiarla con diferentes exenciones y prerrogativas (...) a fin de que no hallasen impedimento para cuidarla y custodiarla de todo fraude, y que llevados de esta exención se hallasen ministros y estanqueros para los pueblos, que por cortos no sufrían la asignación de sueldo para su manutención ${ }^{56}$.

Entrando de lleno en la discusión política de fondo, el director de la Renta Jacobo Flon argüía que los números le daban la razón, con admiración aun de los mismos que anteriormente la manejaron en lo pasado, y que perjudicar al estanco del tabaco en nombre de una pretendida justicia social no obligaría sino a reforzar todavía más la presión fiscal sobre los productos de primera necesidad. Como vemos, el fundamento teórico del monopolio era un argumento realmente operativo.

La función de atracción o de retribución que ejercía el privilegio quedaba manifestada claramente cuando ante su repentina ausencia

casi todos los arrendadores han reclamado a esta Dirección General con quejas y protestas de la inobservancia de contratos que, si subsisten, no podrán aprontar las mesadas, en fe de ser ineficaces sus providencias para poder recaudar la renta, faltándoles administradores y estanqueros para manejarla, porque se les despiden diariamente ${ }^{57}$.

En noviembre de 1728 y luego nuevamente en febrero ${ }^{58}$, la Dirección siguió amenazando con la ruina completa de la Renta de mantenerse el estado de cosas decretado en mayo de 1728. En julio de 1729, una Real Resolución halló una suerte de solución intermedia:

contribuyan en el gasto de alojamientos, según el repartimiento que con igualdad a los demás vecinos, se les hiciere a proporción del que habían de tener si se alojasen los soldados en sus casas, como así se está practicando en el reino de Galicia59.

Finalmente, en 1731 se volvió simple y llanamente a la situación anterior a $1728^{60}$.

56 Íb.

57 Íb.

58 AGS, DGR, $2^{\mathrm{a}}$ remesa, leg. 4803, fecha de expediente: 16/11/1728; y, AGS, DGR, $2^{\mathrm{a}}$ remesa, leg. 4661, fecha de expediente: 2/2/1729.

59 Real Resolución de 13/7/1729 (AGS, DGR, $2^{\mathrm{a}}$ remesa, leg. 4737).

60 Real Provisión de 9/7/1731 (AHN, FC, MH, leg. 7389, f. 197 recto). 
La política de protección y garantía para los empleados de la Renta chocó de continuo con la densa malla de intereses creados de la España del Antiguo Régimen. La Renta del Tabaco tuvo que bregar incansablemente desde su establecimiento por estos privilegios para sus empleados. La historia de sus exenciones se remonta, como ya hemos dicho, al mismo momento de la creación del estanco. El resultado fue en términos generales muy satisfactorio para la Renta del Tabaco, a pesar de las intensas resistencias a que hubo de hacer frente. Todavía en 1767, el secretario de Hacienda Miguel Múzquiz escribía estas consideraciones:

Los señores reyes antecesores concedieron a los dependientes de ella exención de dichas cargas. El Consejo de Castilla siempre ha estado opuesto a ello, y en varios tiempos ha logrado dejar ilusoria esta concesión, pero habiendo acudido al nuestro rey don Felipe $\mathrm{V}$ haciendo presente (con varias circunstancias ocurridas desde la fundación de la Renta) que si no se mantenía a dichos dependientes en el goce de las citadas exenciones, se vería arruinada una de las joyas más preciosas de la Monarquía, acordó Su Majestad renovarlas y ampliarlas, comunicando su real decreto a la Junta, por quien se expidieron las cédulas correspondientes a todos los pueblos de España. Este es un punto que merece mucha consideración, y a la verdad que si no se les continúa a los dependientes de la Renta en las quietas y pacíficas posesiones de la expuesta exención, no respondemos de los valores de la Renta, que decaerá absolutamente ${ }^{61}$.

La evolución del régimen de personal de la Renta del Tabaco fue, por lo tanto, manifestación clara de una importante tendencia política de la España del siglo XVIII: el traslado de los privilegios desde los cuerpos tradicionales hacia la Administración, con el fin de fortalecer al Estado, o dicho de otro modo, asistimos a una redistribución de los beneficios del privilegio en función de su mayor utilidad para el Estado. El absolutismo no pretendió eliminar el privilegio, sino cambiarlo de sitio, utilizando de este modo uno de los elementos más definitorios del Antiguo Régimen para fortalecer la autoridad del Estado frente a los viejos poderes estamentales ${ }^{62}$. La legislación del Tabaco tendió siempre a hacer iguales ante la Renta a todos los vasallos del rey. Siendo el monopolio del tabaco una fuente de ingresos básica para el Estado, no podía éste consentir que, amparándose en fueros y privilegios, hubiese quien defraudase los intereses reales en $\tan$ sustanciosa materia o se evitase su represión con insalvables obstáculos ${ }^{63}$. Pero si la Renta del Tabaco significó en su exclusividad jurisdiccional un paso hacia la igualdad, la organización de la misma Renta introdujo nuevos elementos de privilegio para sus integrantes, siguiendo el mismo criterio del interés hacendístico de un Estado con voluntad de fortalecerse.

61 Órdenes de 27/8, 14/10, 29/10 y 3/11/1767 (AHN, FC, MH, lib. 7390, f. 312 recto).

62 Un proceso similar es estudiado por ANDUJAR, Francisco: «El fuero militar en el siglo XVIII: un estatuto de privilegio», en Chronica Nova (Granada), 23 (1996), pp. 11-31.

63 Cf. Escobedo, R.: El tabaco del rey..., pp. 254-291. 